\title{
One-year observation of leflunomide effectiveness and saftey in juvenile idiopathic arthritis : a clinical practice review (preliminary data)
}

\author{
V Torrente-Segarra ${ }^{1,2^{*}}$, P Santín ${ }^{1}$, L Casas $^{3}$, S Ricart ${ }^{1}$, R Bou ${ }^{1}$, JB Ros ${ }^{1}$, N Rodríguez ${ }^{4}$, J Antón López
}

From 18th Pediatric Rheumatology European Society (PReS) Congress

Bruges, Belgium. 14-18 September 2011

\section{Objectives}

To assess efectiveness and safety of leflunomide (LFN) in juvenile idiopathic arthritis patients (JIA).

\section{Methods}

We performed a retrospective medical charts review in all JIA patients who received LFN between Jan 2006 to Mar 2011 from our outpatient Pediatric Rheumatology Clinics. We collected data of: gender, age, type of JIA, date of onset, date of diagnosis, date of first DMARD, uveitis, reason to indiciate LFN, concomitant therapies, reason to discontinuation, joint activity (tender and swollen, low rang of motion count), and biological markers at baseline, 3 and 12-months follow-up.

\section{Results}

We found 32 patients had used LFN sometime. Patients received oral $20 \mathrm{mg} /$ daily LFN as compassionate therapy after methotreate use (at conventional dosage of 10$15 \mathrm{mg} / \mathrm{m} 2$ ), in all cases. We present data from the first 14 patient medical charts reviewed. Female 11 and 3 Male; 7/14 olygoarticular ANA positive, 3/14 uveitis; 11/ 14 maintained LFN after one year-follow up. Reason: 5 due to partial response, 5 due to adverse event, and 4 due to intolerance, to methotrexate. $7 / 14$ received combined therapy with etanercept, and 3/14 with infliximab. 10/14 (71\%) received LFN for at least one year, $2 / 14$ (14\%) withdrawn LFN use due to clinical remission.

\begin{tabular}{llll}
\hline${ }^{*}$ median & baseline & $3 \mathrm{M}$ & $12 \mathrm{M}$ \\
\hline SJC & 2.54 & 0.64 & 0 \\
\hline TJC & 2.61 & 1.07 & 0.07 \\
\hline LRMC & 2.14 & 1.57 & 0.92 \\
\hline
\end{tabular}

\section{Conclusions}

$71 \%$ of patients who received LFN showed efficacy and only $14 \%$ had adverse events (recovered). Most were ANA positive oligoarticular JIA, and 2 more had uveitis.

Safety seemed acceptable either alone or with antiTNF concomitant use.

\section{Author details}

'Pediatric Rheumatology Unit, Hospital Sant Joan de Déu, Barcelona, Spain. ${ }^{2}$ Rheumatology Department, Hospital General Hospitalet, Barcelona, Spain. ${ }^{3}$ Rheumatology Department, Hospital Nuestra Señora Candelaria, Canarias, Spain. ${ }^{4}$ Rehabilitation Department, Hospital Sant Joan de Déu, Barcelona, Spain.

Published: 14 September 2011

\section{doi:10.1186/1546-0096-9-S1-P176}

Cite this article as: Torrente-Segarra et al:: One-year observation of leflunomide effectiveness and saftey in juvenile idiopathic arthritis : a clinical practice review (preliminary data). Pediatric Rheumatology 20119 (Suppl 1):P176.

* Correspondence: vtorrente@hsjdbcn.org

'Pediatric Rheumatology Unit, Hospital Sant Joan de Déu, Barcelona, Spain

Full list of author information is available at the end of the article

(c) 2011 Torrente-Segarra et al; licensee BioMed Central Ltd. This is an open access article distributed under the terms of the Creative 